\title{
WEB STORAGE BERBASIS PRIVATE CLOUD MENGGUNAKAN ENKRIPSI SHA1 PADA GBKP KM 8 PADANG BULAN MEDAN
}

\author{
${ }^{1}$ Fati Gratianus Nafiri Larosa, ${ }^{2}$ Jimmy F. Naibaho, ${ }^{3}$ Romeo Mamanta Tarigan \\ ${ }^{1,2,3}$ Fakultas Ilmu Komputer, Universitas Methodist Indonesia \\ Email: ${ }^{1}$ fatignlarosa@gmail.com
}

DOI: https://doi.org/10.46880/jmika.Vol4No1.pp56-59

\begin{abstract}
ABSTRAK
GBKP km 8 Padang Bulan Medan mempunyai kendala dalam memonitor, mengatur, dan mengelola data secara cepat, efektif dan efisien, yang selama ini masih bersifat konvensional sehingga mengakibatkan tingginya biaya operasional. Pembangunan aplikasi web storage berbasis private cloud, dimaksudkan untuk menjawab kesulitan di atas. Konsep private cloud computing harus mengedepankan faktor keamanan file-file yang disimpan pada server private cloud tersebut dengan menggunakan salah satu algoritma yakni SHA1. SHA1 digunakan sebagai autentikasi, integritas dan digital signature. Akses terhadap web storage melalui koneksi intranet secara Local Area Network.
\end{abstract}

Kata Kunci: Private Cloud Computing, Web Storage, FreeNAS, SHA1, GBKP

\section{PENDAHULUAN}

GBKP km 8 Padang Bulan, Medan merupakan salah satu gereja yang memiliki jemaat yang cukup banyak. Penyimpanan dan pengolahan data masih tersebar pada masing-masing komputer pengguna. GBKP $\mathrm{km} 8$ mempunyai kendala dalam memonitor, mengatur, dan mengelolah data secara cepat. Di samping itu, diseminasi informasinya masih bersifat manual (konvensional) sehingga tinggi biaya operasional yang dikeluarkan. Sebagai contoh dalam pengolahan data informasi warta jemaat. Di setiap minggu pihak gereja GBKP $\mathrm{km} 8$ harus mencetak warta jemaat dalam jumlah exemplar yang banyak.

Konsep web storage pada private cloud computing digunakan untuk penyimpanan dan pengolahan data dalam organisasi gereja GBKP ini tidak lepas dari masalah-masalah yang berhubungan dengan keamanan data yang disimpan di server tersebut. Kombinasi dengan kriptografi menjadi salah satu solusi untuk mangatasi masalah keamanan di private cloud. Salah satu algoritma yang dapat menjaga keamanan data adalah SHA1 yang digunakan sebagai autentikasi, integritas dan digital signature.

\section{KAJIAN LITERATUR Web Storage \\ Web storage yang merupakan bentuk penyimpanan berbasis cloud sering juga disebut sebagai cloud storage. Beberapa contoh cloud storage yang disediakan oleh pihak ketiga misalnya Simple Storage Service (S3) dari amazon.com, juga tersedia dari IBM, Google dan EMC. Web storage dibangun}

dengan Sistem Operasi NAS (Network Attached Storage) yakni FreeNAS yang memiliki kelebihan antara lain ukuran file yang cukup kecil, mudah dikonfigurasi, dan memiliki kelengkapan fitur dan layanan (Veer, 2017).

\section{Private Cloud Computing}

Cloud computing merupakan user-centric bukan $P C$-centric. Semua data dan aplikasi atau software tersimpan di server sehingga tidak perlu dilakukan instalasi pada komputer pengguna. Namun pengguna harus terhubung ke internet atau intranet untuk dapat akses ke server cloud computing (Miller, 2008).

Penggunaan web storage sebagai Infrastructure as a Service (IaaS) berbasis private cloud computing mempunyai keunggulan jika dibandingkan dengan media penyimpanan perangkat keras seperti CD/DVD, hard disk, portable disk, flashdisk atau bentuk yang lain, yakni (Basri, 2015):

- Skalabilitas; dapat disesuaikan dengan kebutuhan dari pengguna. Dengan penambahan perangkat keras, sebuah penyedia layanan Cloud Storage bisa meningkatkan kapasitasnya.

- Aksesbilitas; kemudahan ketika menggunakan layanan tersebut seperti mengunduh, membuka atau melakukan editing terhadap data yang telah tersimpan kapan pun dan di manapun selama perangkat masih terkoneksi internet/intranet. 


\section{FreeNAS}

Salah satu distro Linux yang digunakan dalam berbagi penyimpanan adalah FreeNAS yang berbasis FreeBSD, di mana suatu volume atau partisi suatu hardisk digunakan secara bersama oleh sejumlah server. FreeNAS mendukung banyak sistem operasi serta berbagai host virtualisasi seperti Xen Server, VMWare, Oracle VM VirtualBox dan sebagainya.

FreeNAS dikelola melalui web interface yang mendukung konfigurasi storage pool, user management, sharing confuguration dan system maintenance (Veer, 2017).

\section{Secure Hash Algorithm (SHA)}

Secure Hash Algorithm (SHA) merupakan fungsi Hash yang bersifat "tidak dapat diubah kembali" menjadi pesan semula (satu arah) yang akan menghasilkan sebuah checksum atau fingerprint dari data tersebut. Umumnya dipergunakan untuk data integration dan authentication. Kelebihan fungsi Hash yaitu menjaga integritas data, hemat dalam waktu pengiriman serta menormalkan panjang data yang beraneka ragam.

Fungsi Hash yang dipakai untuk paper ini adalah SHA1 yang memetakan inputan string dengan panjang sembarang menjadi suatu nilai hash dengan panjang tetap yaitu 160 bit. Ukuran internal state pada SHA 1 adalah 160 bit, sedangkan ukuran bloknya adalah 64 bytes (Kurniawan, 2017).

\section{METODOLOGI PENELITIAN}

Analisis Sistem

Kebutuhan umum bagi warga Jemaat Gereja GBKP Km 8 berupa:

- Tampilan tentang GBKP Km 8

- Tampilan Kegiatan

- Data Jemaat / anggota GBKP Km 8

Kebutuhan admin sebagai pengelola web storage adalah:

- Melakukan proses login terhadap sistem

- Menambahkan/mengedit data jemaat Gereja GBKP Km 8

- Mengolah data jemaat, data sektor, data kegiatan

\section{Penerapan Algoritma SHA1}

Implementasi web storage berbasis private cloud pada GBKP Km 8 menggunakan enkripsi SHA1 seperti yang tertera pada Gambar 1 .

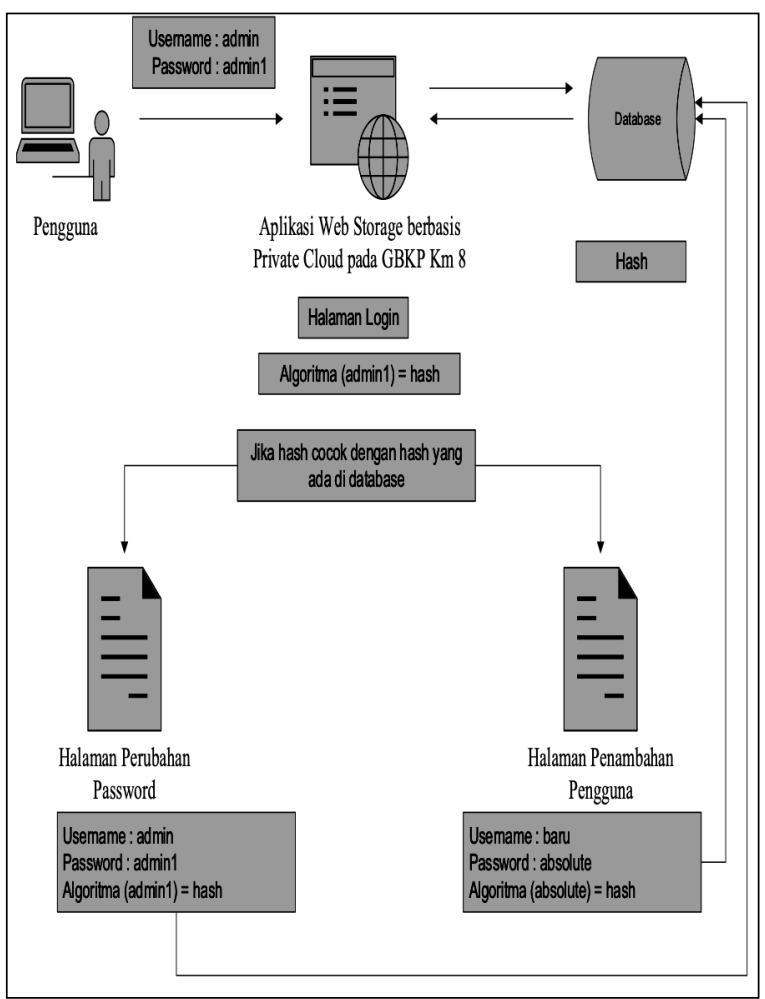

Gambar 1. Penerapan Algoritma SHA1

\section{Flowchart Penerapan Algoritma SHA1}

Flowchart penerapan Algoritma SHA1 pada proses login ditampilkan seperti Gambar 2 di bawah ini.

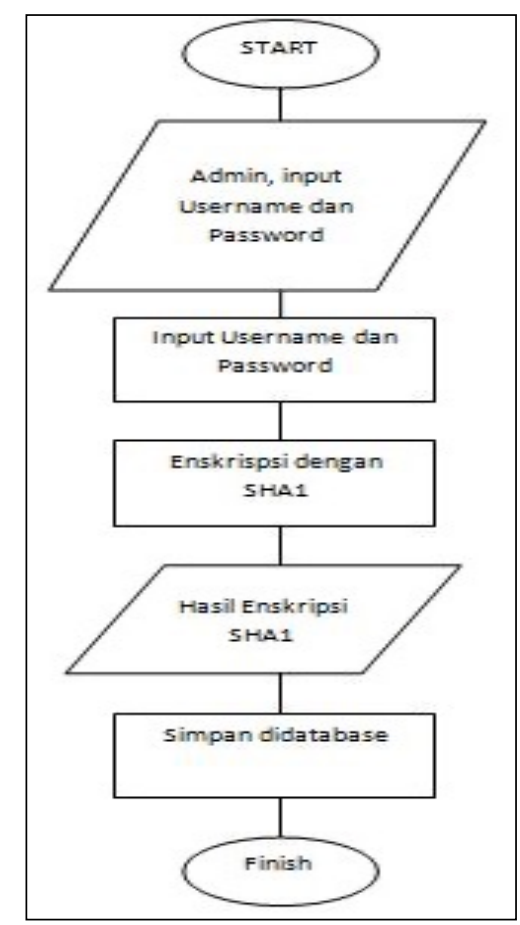

Gambar 2. Flowchart Proses login 


\section{HASIL DAN PEMBAHASAN}

\section{Tampilan Login Admin}

Tampilan Login Admin menggunakan email account seperti Gambar 3 di bawah ini.

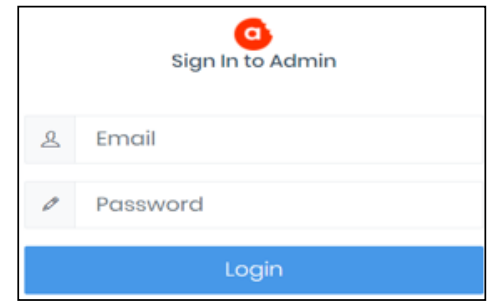

Gambar 3. Tampilan Login Admin

\section{Tampilan Login Jemaat}

Tampilan Login Jemaat menggunakan email account seperti Gambar 4 di bawah ini.

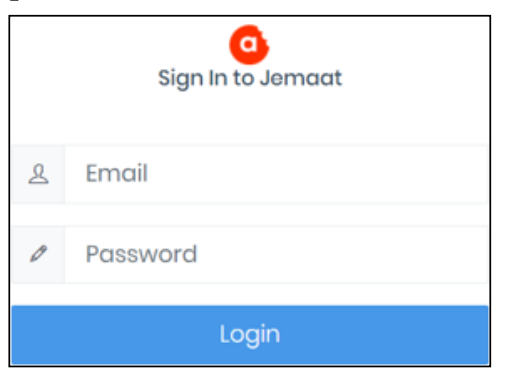

Gambar 4. Tampilan Login Jemaat

\section{Tampilan Dashboard}

Tampilan Dashboard berisi beberapa menu seperti Gambar 5 di bawah ini.

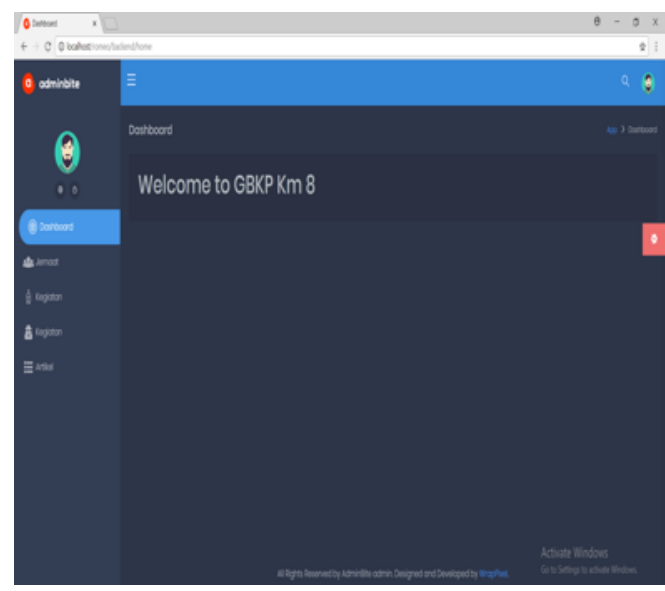

Gambar 5. Tampilan Dashboard

\section{Tampilan Data Jemaat}

Tampilan Data Jemaat GBKP Km 8 seperti Gambar 6 di berikut.

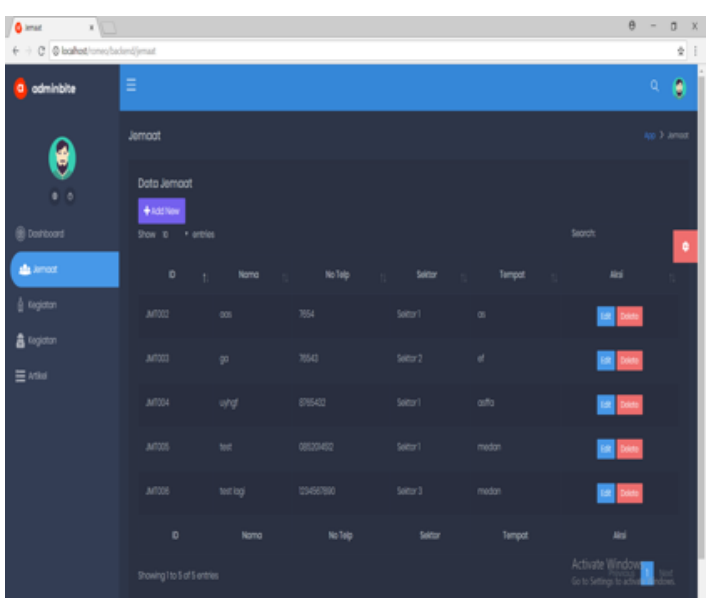

Gambar 6. Tampilan Data Jemaat

Tampilan Kegiatan

Tampilan Kegiatan berisi data kegiatan yang ada di GBKP Km 8 seperti pada Gambar 7 di bawah ini.

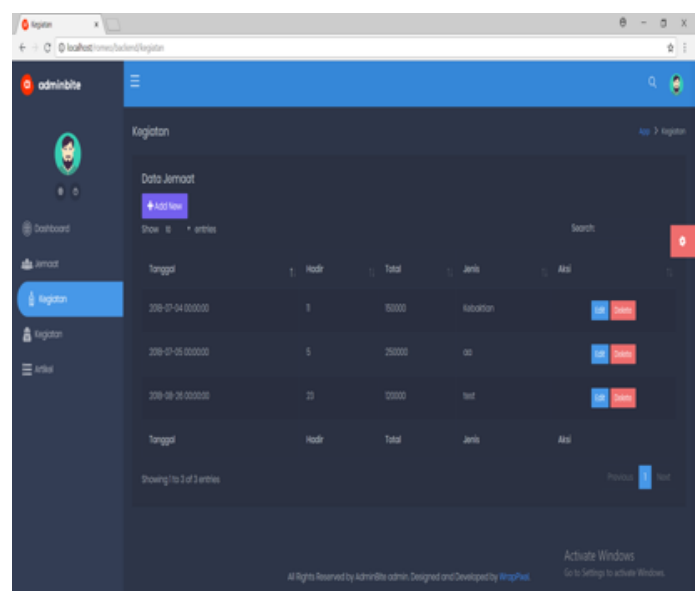

Gambar 7. Tampilan Kegiatan

\section{Tampilan Artikel}

Tampilan Artikel menampilkan artikel-artikel yang berkaitan dengan kegiatan gerejawi seperti pada Gambar 8 .

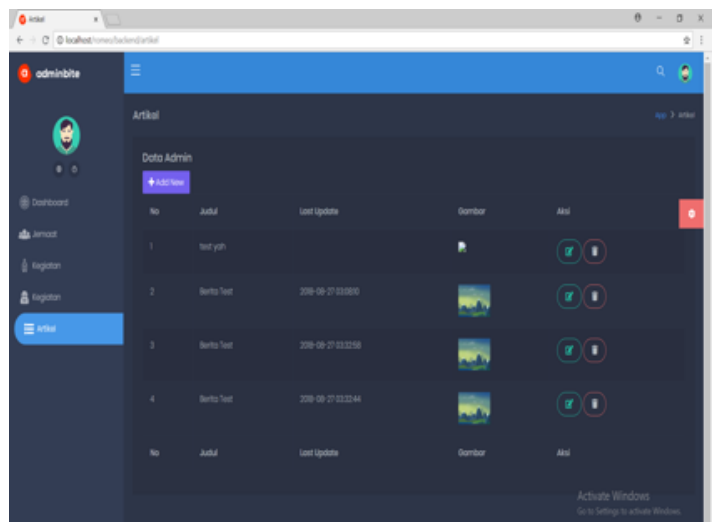

Gambar 8. Tampilan Artikel 


\section{Tampilan My Profile}

Tampilan My Profile dapat dilihat pada

Gambar 9 di bawah ini.

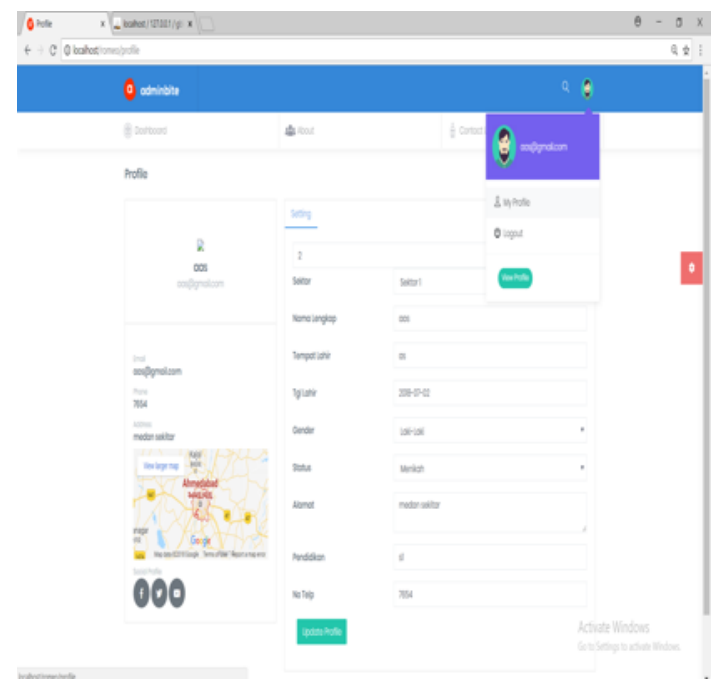

Gambar 9. Tampilan My Profile

\section{KESIMPULAN}

Berdasarkan hasil perancangan dan pengujian yang dilakukan, maka diambil kesimpulan yakni:

- Web Storage berbasis private cloud computing berhasil dibangun layanan Infrastructure as a Service (IaaS) yaitu layanan yang diberikan dengan cara menyediakan komponen-komponen berupa server, hardware, dan jaringan yang dibutuhkan dalam menyediakan sebuah mesin server.

- Algortima SHA1 berhasil diterapkan pada sistem web storage berbasis private cloud computing pada GBKP Km 8 untuk mengamankan proses login.

\section{DAFTAR PUSTAKA}

Basry dan Asril (2015). Penyimpanan data berbasis cloud sebagai mitigasi bencana kerusakan data. Journal Of Informatics Engineering, 6(2), 250252.

Fauziah, Y., (2014). Arsitektur cloud computing pada sistem informasi desa sebagai layanan akses informasi desa. Prosiding Seminar Nasional Informatika 2014 (semnasIF 2014), pp. 224230

Kurniawan, F., dkk. (2017). Analisis dan implementasi algoritma sha-1 dan sha-3 pada sistem autentikasi garuda training cost. Jurnal Pengembangan Teknologi Informasi dan Ilmu Komputer, 1(9), 803-812.
Miller, M., (2008). Cloud Computing: Web-Based Applications That Change The Way You Work Collaborate Online. Que.

Santiko, I., dkk., (2017). Pemanfaatan private cloud storage sebagai media penyimpanan data elearning pada lembaga pendidikan. Jurnal Teknik Informatika, 10(2), 137-146.

Veer, R. and Larosa, F.G.N., (2017), Perancangan webstorage menggunakan freenas 8 berbasis private cloud (studi kasus fakultas ilmu komputer universitas methodist indonesia), Majalah Ilmiah METHODA, 7(3), 55-63. 